\title{
New products and
}

\section{focus on implants and imaging}

Please send product news information and images to Kate Maynard at the $B D J$,

Nature Publishing Group, The Macmillan Building, 4-6 Crinan Street, London N1 9XW. Product news is provided as a service to readers using text and images from the manufacturer, supplier or distributor and does not imply endorsement by the $B D J$. Normal and prudent research should be exercised before purchase or use of any product mentioned.

\section{DENTURES WITH SUPER SUCTION}

Biomedics NZ has invented a new type of denture with a better seal and fewer undesirable effects such as 'shrinkage' of the gum. Ultra Suction Dentures use a valve system to create suction against the gums, keeping the dentures in place.

Ultra Suction Dentures have a specially designed profiled bar that is capable of remodelling the alveolar ridge, thus creating and maintaining a seal around that area.

Two tiny Ultra Suction valves are inserted into the denture, one each side. Once the denture is in place in tight occlusion, the gingival tissues penetrate the suction chamber. The air is expelled through the valves and the diaphragms prevent its reintroduction. The lower pressure beneath the denture exerts a pull and seals off the new alveolar ridge periphery.
At the patient's first attempt to swallow, the vacuum created in the mouth eliminates any air left in the suction chamber. The result is a better fit to the tissues and improved resistance to dislodging forces. The denture can be removed simply by lifting it up.

For those who already have dentures, Biomedics NZ has a retro-kit that dentists can use to adapt the dentures to the suction technology.

www.ultrasuction.com

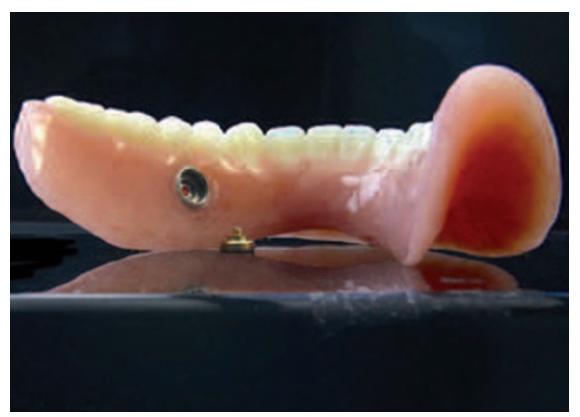

\section{HOT PINK SELLS LIKE HOT CAKES}

Strong sellers for Simon Jersey, part of Europe's leading professional wear provider Kwintet, include tunics with a red asymmetric design and a hot pink variation.

The design team at Simon Jersey have revolutionised the styling and fitting of their dental team uniform in recent years and are also conscious of health and safety concerns.

Poppers for practicality and pockets for functionality have been included on new tunic designs as added features. The new One Popper Tunic is 65\% polyester and 35\% cotton, a practical fabric for dentistry as it is easy care, comfortable and absorbent.

Simon Jersey design their colour selections to be warm and inviting but with a clinical edge that suggests the wearer is in control and confident. Dental receptionists and practice managers will also find suiting and accessories complementary to their dental team's selection available in Simon Jersey's range.

The full Simon Jersey range can be viewed at www.simonjersey. com, or call 08444994414 for more information.

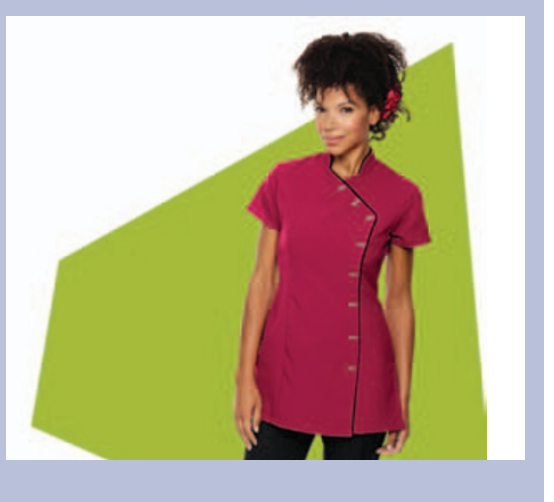

